\title{
Cortesía e imagen en las preguntas orales del Parlamento español
}

\author{
CATALINA FUENTES RODRÍGUEZ
}

UNIVERSIDAD DE SEVILLA

ABSTRACT: This article aims to politeness in Spanish question time. In these, the norm is the conflict, and the impoliteness is normal to the members of the opposition. The government has to protect their face and be collaborative. In these interactions, with a fixed structure, indirect forms are mixed to direct attacks. These attacks have different weight according to the politicians.

Keywords: Question time, parliamentary discourse, politeness, face, discourse analysis.

RESUMEN: en este artículo nos acercamos al comportamiento de la cortesía en las preguntas orales del Parlamento español. En ellas lo habitual es el enfrentamiento, creando una descortesía normativa de parte de la oposición. El gobierno, por su parte, debe defender su imagen y ser colaborativo. En estas interacciones, de estructura perfectamente fijada, se mezclan formas indirectas con ataques directos, en diferente grado según los participantes.

Palabras clave: preguntas orales, discurso parlamentario, cortesía, imagen, análisis del discurso.

Las preguntas orales en el Parlamento constituyen un tipo discursivo especial, ya que es la oportunidad para la oposición de obtener una respuesta a sus preguntas, orientar los debates y mostrar su desacuerdo con el gobierno. Como ya demostramos en otro lugar (Fuentes Rodríguez, 2010 a), el fin de este 
texto es atacar al gobierno y conseguir «a political point»1 (Pérez de Ayala 2001: 144). Todos los actos de habla realizados están orientados a ello. Por eso, el nivel de enfrentamiento es muy elevado y el empleo de la cortesía relevante.

En español este discurso tiene una estructura discursiva bien marcada y limitada en su duración: solo dos intercambios. Los diputados eligen el tema, que debe presentarse bajo forma de pregunta, aunque el fin pretendido no sea ese (Fuentes Rodríguez, 2010 a). En la segunda intervención, el diputado muestra claramente su intención, y acusa al gobierno. Por ello el grado de descortesía en este es muy alto. Su fin es el ataque a la imagen del Ejecutivo, aunque no siempre se exponga de forma directa. Descubrir las estrategias empleadas en estas operaciones de imagen es el objetivo de este trabajo. ${ }^{2}$

\section{2.}

Chilton-Schäffner (2002: 14) consideran que el tema de la cortesía es fundamental en el texto político, ya que la metáfora utilizada en esta teoría, la noción de territorio, es básica en él. Y añade que «in political situations, the FTA is likely to have variable value for different groups of hearers; so the linguistic formulations are chosen carefully». Lo mismo ocurre con las manifestaciones de cortesía. Algunas de ellas pertenecen a la rutina de ese texto. Así, el uso de usted, o señoría, o incluso la forma interrogativa en este caso textual concreto de las preguntas orales. Dice Arce (2006):

En esta dinámica, el político-parlamentario utiliza constantemente formulaciones que en otros contextos supondrían actos corteses (agradecimientos) o actos atenuados, pero que, en cambio, en este tipo de lenguaje no son usados con ese propósito sino con la intención simplemente de ser correctos según el formulismo impuesto [...] El parlamentario recurre de manera continua al empleo mecánico, casi sistemático, de dichas formas, las cuales son usadas más como instrumentos formales, como una cuestión de norma, que con aquellos valores que las caracterizan. (233-235)

1. Questions are «part of a political battle in which party points are scored and personal or party glory pursued» (Borthwick, 1993: 103). Cfr. Pérez de Ayala (1996, 2001), Franklin-Norton (1993). En los estudios sobre entrevistas se ha demostrado que las preguntas totales es un procedimiento para el discurso de confrontación. Vid Heritage $(2002,2003)$ y Emmertsen (2007).

2. Este trabajo se enmarca dentro de las actividades del proyecto de I+D+i FFI 2009-10515, «(Des)cortesía y medios de comunicación: estudio pragmático», subvencionado por el Ministerio de Ciencia e Innovación (Gobierno de España). 
Brown-Levinson (1987) ya fijaron este tipo de discurso como el prototipo de concentración de ataques a la imagen. ${ }^{3}$ Esto es más acusado en la question time, que se define precisamente por tenerlo como objetivo primordial:

When MPs table questions for oral answer, they usually look for the occasion to attack the Government, or support it. Thus, every question or parliamentary exchange can be considered a global FTA (Johnson, 1992), and the whole activity of Question Time in the House of Commons a face-threatening genre. (Pérez de Ayala 2001: 145-6).

Para esta autora la imagen pública del gobierno se pone en peligro. Es la base del funcionamiento del debate, que se convierte en una lucha. Boulton (1992: 8) insiste en que «[t]he whole character of proceedings in the Chamber is adversarial, but what the electorate is entitled to see is 'a good, clean fight'». En el parlamento británico, el tratado de May (1989) intenta controlar los ataques a la imagen personal del político, ${ }^{4}$ pero permite aquellos que se exponen de forma indirecta. Reacciona contra el insulto personal («personal allusions and unparliamentary expressions»), ${ }^{5}$ pero permite la forma velada de exponerlo. Esto le lleva a decir que es un texto donde se muestra la hipocresía del lenguaje político. Las normas obligan a tener un lenguaje parlamentario (moderación y good temper), al cual hay que adaptarse, pero siguiéndolo, prácticamente todo se puede decir.

En May (1989) se prohíbe lo siguiente:

1 The imputation of false or unavowed motives. (.)

2 The misrepresentation of the language of another and the accusation of misrepresentation.(.)

3 Charges of uttering a deliberate falsehood. (.)

4 Abusive and insulting language of a nature likely to create disorder. (Pérez de Ayala 2001: 149)

Si estas ofensas se dirigen al partido, se tiene cierta consideración.

En el Parlamento español la prohibición se limita a:

3. Cfr. Harris (1991, 2001), Fuentes (2010 a, b, 2008).

4. «Relations between MPs can become difficult, and the potential for aggression is high. Yet, communication is possible, partly due to the presence of Erskine May's Treatise on the law, privileges, proceedings and usage of Parliament, with norms that affect, among other things, both the content and form of speeches, debates and questions» (Pérez de Ayala, 2001: 144).

5. In order to guard against all appearance of personality in debate, no Member should refer to another by name. Each Member must be distinguished by the office he holds, by the place he represents or by other designations, as (.) 'the honourable' or 'right honourable gentleman the Member for York', or 'the honourable and learned Member who has just sat down' or, when speaking of a member of the same party, 'my (right) honourable friend the Member for.'.» (May, 1989: 380). 
Cuando profirieren palabras o vertieren conceptos ofensivos al decoro de la Cámara o de sus miembros, de las Instituciones del Estado o de cualquiera otra persona o entidad (Reglamento del Congreso, art. 103, http://www.congreso.es).

En estos casos el Presidente de la Cámara puede expulsar al diputado. El resto de advertencias corresponde al funcionamiento: «Cuando en sus discursos faltaren a lo establecido para la buena marcha de sus deliberaciones. $3^{\circ}$ Cuando con interrupciones o de cualquier otra forma alteren el orden de las sesiones».

En el caso de proferir ofensas, «el Presidente requerirá al Diputado u orador para que retire las ofensas proferidas y ordenará que no consten en el 'Diario de Sesiones'» (Art. 104, punto 3). En el 106 se habla de «desorden grave con su conducta de obra o palabra, será expulsado», y en 107: «Quienes en estas dieran muestras de aprobación o desaprobación, perturbaren el orden o faltaren a la debida compostura, serán inmediatamente expulsados del Palacio» (punto 2).

Estamos, pues, ante un género marcado por la descortesía, donde lo que se prohíbe es el enfrentamiento directo. Por ello, lo más frecuente es el uso de formas indirectas, o, como vamos a ver, una combinación de forma cortés con contenido descortés. En este discurso la norma es la descortesía (frente a la visión de Brown-Levinson), que se convierte en característica del género, como en todo el discurso parlamentario (Fuentes Rodríguez, $2009 b, 2010 b$ y $c$ ). «A new concept of face-work emerges, that of 'face-work as aggression', described by Calvo (1991) for the interaction between master and fool in Shakespeare», concluye Pérez de Ayala (2001: 164).

Por tanto, el contexto interactivo predetermina el ataque. En el congreso van a atacar y ser atacados. Lo importante es ser más brillante que el contrario: ${ }^{6}$ «The function of politeness changes: politeness strategies are not the linguistic means necessary to avoid conflict. Question Time is conflict» ${ }^{7}$ (Pérez de Ayala, 2001: 165). Es decir, no se trata de obtener información sobre un dato concreto, sino acosar al Ejecutivo, y conseguir desestabilizar al gobierno, mostrar su debilidad. En suma, realizar su tarea de oposición, de crítica, de la forma más brillante posible. Es un duelo cuerpo a cuerpo con el gobierno. De ahí su atractivo, su frescura, y también su alto grado de enfrentamiento. Estamos, pues, ante lo que podemos denominar descortesía normativa.

6. Cfr. Goffman (1967: 25), Fuentes Rodríguez 2010 b, y también Calvo (1991: 98): «The winner proves that he can make his interlocutor lose face, and that he can easily fend off any threats posed to his own face. As Goffman says, conveying this information becomes the real topic of the talk, "what the talk is about'. The interpersonal takes here precedence over the ideational: the referential content conveyed by the dialogue is pushed to the background whereas interpersonal relations come to occupy the foreground».

7. Cfr. Fuentes Rodríguez (2010 a), Fuentes-Alcaide (2008, 2010), Fuentes et al. (2011), Van Dijk (2000, 2004), Chilton (2002, 2004), Bayley (2004, ed.), Wilson (1990). 
En este entorno, debemos analizar la interacción verbal, que presenta unos papeles muy definidos y polarizados:

- El que pregunta es el atacante, miembro de la oposición. Está legitimado para ser duro, pero de forma indirecta, formalmente cortés. A veces lo respeta y otras pasa a la acusación personal, al ataque ad personam.

- El que responde, el gobierno, está obligado a ello. A veces lo respeta, otras utiliza la evasión y no responde (Rasiah, 2010; Fuentes Rodríguez, 2010 a), y otras sucumbe al ataque y lo devuelve de forma agresiva, mostrando poder, autoridad (Cfr. asimismo Bull, 1994, 2003; Bull-Mayer, 1993).

En la primera pregunta se intenta, con alguna excepción, respetar lo fijado por la cortesía y el tipo de género: contiene una pregunta, aunque su intención sea atacar y desacreditar. Ya en la segunda intervención del diputado se llega a la acusación. En las respuestas, la colaboración suele ser la tónica por parte del gobierno, y el uso de formas indirectas, que atenúan el grado de descortesía, aunque va a variar según quién sea el diputado y el ministro que responda.

La imagen que se pone en juego es múltiple. En primer lugar, es la imagen pública del político, es decir, su imagen de rol (Goffman, 1959, 1967; Bravo, 2001, 2005; Bravo-Briz, 2004; Blas Arroyo, 2003) como miembro del gobierno o de un determinado partido. A ella hay que añadir otras que actúan de forma simultánea: la individual, la del propio grupo como colectivo y la que se adapta a su función argumentativa en ese texto. En el caso del gobierno, hay que añadir la imagen social del Ejecutivo como el que detenta el poder, con lo que la relación que establece es asimétrica. Por otra parte, en la imagen individual tienen que defender el rol que han desempeñado en su función como político, o en su forma de hablar de determinados temas. Por ejemplo, Zapatero ha creado una imagen cercana, colaborativa, lo que se ha dado en llamar el «talante». También tiene como misión ofrecer una imagen positiva ante la crisis, lo cual le lleva a usar formas positivas en su mensaje, y a transmitir confianza.

En el análisis de la cortesía en estas preguntas, tenemos que diferenciar entre las dirigidas al presidente del gobierno y las que responden otros miembros del Ejecutivo. Las primeras suelen estar realizadas por el portavoz o presidente del grupo parlamentario, aunque, evidentemente, puede haber otros. En ellas es más fácil que la relación se establezca de forma más ritual y derive a un remedo del enfrentamiento que tienen en la cámara. Suelen ser menos directas y en ellas la evasión es un rasgo fundamental, tanto por parte del que pregunta como del que responde. Se utilizan las formas indirectas en un mayor grado y se rehúye la respuesta (Cfr. Brown-Levinson, 1987; Fuentes Rodríguez, e. p.) 


\section{Preguntas dirigidas al presidente del gobierno}

\subsection{Colaborativa, ofreciéndole la mano. Cortés:}

El señor RAJOY BREY: Señor presidente, le voy a hacer una propuesta deliberativa también, y es que venga aquí a deliberar sobre un asunto importante. Como usted sabe, durante la práctica totalidad del pasado año y sobre todo en los últimos meses ha habido un debate a nivel internacional muy intenso sobre la redefinición de la estrategia en Afganistán. Además, como usted también sabe, tenemos ahora muchos más soldados que cuando usted, en el año 2008, dijo que no enviaría más soldados a Afganistán. Después fueron 220, después el Batallón Electoral -es verdad que ya ha vuelto- y ahora pretenden que vayan 500 soldados más a Afganistán. Por otra parte, la operatividad de nuestro ejército hoy es mayor y es obvio que estamos ante un escenario bélico. Es lógico, por tanto, que una vez que las cosas hayan cambiado, y puesto que usted desde el año 2004 no ha debatido sobre este asunto en las Cortes, venga. Por tanto, el sentido que tiene esta intervención es decirle que debe venir aquí, porque es un tema importante para el mundo pero también para España y los españoles, a explicar la naturaleza de la misión, el coste, la seguridad y sobre todo las perspectivas de futuro. Le pido que venga aquí y ya le anuncio por si hubiera alguna duda -que seguro que no la tiene-que yo voy a apoyar y mi grupo también el envío de 500 soldados más a Afganistán, pero creo que los españoles deben saber exactamente, como ha sabido el resto de ciudadanos de otros países que están en Afganistán, por boca de sus jefes de Estado o de Gobierno, los temas a los que yo he hecho referencia. Gracias. (Aplausos.)

El señor PRESIDENTE: Muchas gracias, señor Rajoy.

Señor presidente del Gobierno.

El señor PRESIDENTE DEL GOBIERNO (Rodríguez Zapatero): Señor Rajoy, le agradezco su compromiso. En esto tiene la coherencia que ha mantenido a lo largo del tiempo de apoyar el envío de tropas a Afganistán que hoy va a explicar la ministra de Defensa en Comisión. Usted ha sido coherente. Creo que el Gobierno ha comparecido en muchas ocasiones, pero es un tema de importancia para nuestro país, es la misión más difícil que tenemos y en aras de un buen clima voy a atender su petición y compareceré ante esta Cámara en un pleno.

Por supuesto, eso sí, espero que por parte del conjunto de los grupos sea fijado en una fecha razonable a tenor del calendario y de la agenda que, como consecuencia de la presidencia europea, tenemos en este periodo, pero estoy seguro de que los grupos llegarán a un acuerdo y con ello - estas cosas pasan pocas veces- le doy satisfacción, señor Rajoy. Sí, voy a atender su petición, voy a comparecer en la Cámara sobre Afganistán. Gracias. (DSCD: Diario de Sesiones del Congreso de los Diputados 140, 17-2-2010, 48)

En el caso del jefe de la oposición, la pregunta presentada en el expediente es más fuerte, más descortés que la presentación que hace él de la misma. Parece una reconvención y deja inferir una postura muy negativa ante él: «¿Puede explicar 
el presidente del gobierno por qué no comparece en esta Cámara para explicar el futuro de las tropas desplegadas en Afganistán?» (ídem).

Sin embargo, Rajoy comienza con preámbulos que justifican la situación, aportan datos, establecen guiños y elementos de empatía con el receptor: «como usted sabe...»y tras ellos pasa a exponerlo: «Por tanto, el sentido de esta intervención es decirle que debe venir aquí...», «le pido que venga aquí...». Aunque utiliza formas de obligación («debe venir aquí»), los elementos de colaboración («como usted también sabe») actúan como modificadores realizantes, ${ }^{8}$ elementos de fuerza de su discurso. Tras esto, el mandato $\mathrm{u}$ obligación se convierte en petición («le pido que venga aquí»), y anuncia su apoyo, por lo que se rebaja la tensión. Es colaborativo, cortés.

A ello responde Zapatero agradeciéndolo y accediendo a ello («le agradezco su compromiso. Sí, voy a atender su petición»), aunque añade una objeción con eso sí, una salvedad, restricción. El inicio ha sido cortés, la respuesta también.

\section{2.}

Otro caso es la respuesta evasiva, con formas indirectas que atenúan el enfrentamiento. Este no es personal, no descortés. Los diputados usan lo genérico, argumentos generales, sin personalizar. Llamazares pregunta, argumentando, si va a seguir manteniendo su propuesta de retraso de la edad de jubilación ante la oposición del pueblo. El Presidente responde:

El señor PRESIDENTE DEL GOBIERNO (Rodríguez Zapatero): Gracias, señor presidente.

Señor Llamazares, antes ya me he referido a esta cuestión. El Gobierno cumple con un mandato, con una petición de la Cámara. Hace una propuesta, que incluye la prolongación de la edad de jubilación, sobre el futuro del sistema de pensiones para tener un debate de país sereno, porque lo podemos tener sereno, no tenemos urgencia en cuanto a la solvencia y la solidez del sistema de Seguridad Social. Ese debate es necesario. No hacerlo es irresponsable. No decir a la ciudadanía que dentro de veinticinco años podemos tener problemas en la Seguridad Social por el proceso de envejecimiento de la población y que queremos mantener buenas pensiones, cada día mejores pensiones para todos los que lleguen a la edad de jubilación, sería irresponsable. Vamos a hacerlo. Nuestra propuesta -lo he dicho- en el Pacto de Toledo con los partidos y con los agentes sociales. Estamos abiertos a otras propuestas, a debatirlas, a ponerlas encima de la mesa y a buscar la mejor desde nuestros principios, desde nuestro análisis y desde nuestra posición. Por eso le decía que vaya a la mesa, explique y razone propuestas alternativas. Nosotros vamos a escuchar, y

8. Fuentes-Alcaide (2002), Ducrot (1995). 
como considero que el interés nacional y la Seguridad Social y el sistema de pensiones están por encima de cualquier otra circunstancia, mi deseo y mi compromiso fundamental es un gran acuerdo nacional sobre el futuro del sistema de pensiones. Esa es la posición del Gobierno. Gracias. (Aplausos.) (ídem, 47).

En este primer intercambio, Zapatero muestra una actitud dialogante. Utiliza el argumento de la necesidad del debate. Rebaja la tensión y ofrece diálogo, acuerdo. No ordena, sino que usa: «por eso le decía que...», como forma indirecta. También lo es toda la respuesta. No expresa un no, sino que lo deja inferir por los argumentos que presenta. A partir de aquí Llamazares despliega su argumentación y su ataque. Pero de nuevo no va directo a su persona, sino a su grupo: «ustedes», «les importa un bledo».

El señor LLAMAZARES TRIGO: Gracias, señor presidente.

En un partidario de la democracia deliberativa llama la atención esta respuesta porque es tanto como decir que ustedes tienen iluminación, no sé si divina o de otro tipo, que están convencidos de que la única salvación del sistema de pensiones es su propuesta y, por tanto, que les importa un bledo lo que opina la inmensa mayoría de los ciudadanos, lo que opinan los grupos parlamentarios y lo que opinan los sindicatos [...] rectificar y deberían permitir que en el marco de la Comisión del Pacto de Toledo haya un diálogo sin pies forzados. Su propuesta es un pie forzado. $\mathrm{Su}$ propuesta crea incertidumbre sobre nuestro sistema de pensiones, cuando hasta ahora habían venido defendiendo su viabilidad. Su propuesta crea división en el Pacto de Toledo, en las fuerzas políticas, cuando hasta ahora había habido diálogo. Su propuesta, además, es injusta, señor presidente. Es injusto en un país donde la edad real de jubilación está cerca de los 65 años plantear un objetivo de jubilación más allá de los 65 años, porque ese no es nuestro principal problema. Puede ser de otros países, pero no es nuestro principal problema. Y es injusto también porque ustedes lo hacen calculando la esperanza de vida y no calculando la evolución de la productividad. En estos momentos nosotros gastamos un 9 por ciento del producto interior bruto, tres puntos menos de la media europea en pensiones. Por tanto, no es que seamos unos manirrotos en pensiones. En estos momentos la pensión media española es el 65 por ciento de la pensión media de la Unión Europea y por eso no hay ninguna justificación para esta medida por parte del Gobierno. Esta medida por parte del Gobierno crea incertidumbre en las pensiones públicas y oculta algo muy importante, y es que las pensiones privadas han perdido el 20 por ciento de su valor, y la pregunta consiguiente al Gobierno es: ¿No estarán ustedes beneficiando con estas propuestas las pensiones privadas y perjudicando al servicio público de pensiones? (ídem)

Llamazares repite su propuesta. Añade datos para su argumento, y con por tanto introduce las conclusiones. Presenta la actuación de Zapatero como contraria a sus ideas. Y lo encarna en una forma genérica: «Un partidario de la 
democracia deliberativa», con lo que la crítica se oculta en la impersonalidad. Ahora bien, esto es solo la fachada, porque tras ella deja inferir que su comportamiento va contra la democracia. Tampoco se impone en las expresiones, sino que las presenta como opinión: «Creo que deberían». Y al final la acusación también es indirecta, a través de una pregunta: " « No estarán ustedes...?».

El presidente del gobierno responde también en sentido genérico. Se impone, pero no de forma directa. Reitera, usa su misma base argumentativa (la democracia deliberativa) y lo acusa de faltar a la verdad, pero de nuevo de forma genérica: «Lo que no puede ser... es que no se diga la verdad». Las formas impersonales actúan como otro mecanismo de indirección.

Por tanto, aquí el enfrentamiento se mantiene dentro de la cortesía: en unos casos indirección, elipsis de la respuesta directa, argumentación y ocultación en el grupo.

\section{3.}

La otra posibilidad es el enfrentamiento directo, claramente descortés, de ataque al contrincante. Podemos verlo en la pregunta 180/000994 de Rajoy. Comienza este siendo formalmente cortés. No acusa directamente, sino que emite la cuestión precedida de un preámbulo que dibuja una situación altamente negativa, y lleva al oyente a la conclusión de que no está haciendo nada («Señor presidente, ¿qué va a hacer? ¿Va a seguir igual que la semana pasada, que la anterior, que la anterior, que la anterior y que la anterior?»). Todo ello predispone a una lectura como acusación y no como pregunta.

Zapatero ofrece datos en la primera respuesta, en actitud colaborativa, dentro de una argumentación medida. En el segundo intercambio comienza claramente el ataque y se recrudece. Así, Rajoy lo acusa de ir contra la verdad de forma creciente («Señor presidente, usted no ha dicho la verdad [...] usted no dice la verdad cuando habla del déficit público [...] Por tanto, yo le digo que usted ha dicho mentira en esta Cámara»). Ante esto, Zapatero se reafirma en los datos, lo ataca solo indicando que toca de oído, y le pide al final una actitud más positiva. Su expresión es más dialogante. Su posición también le obliga a justificarse y a proporcionar datos. Es su misión en la Cámara en estas preguntas. Además, debe hacerlo para contrarrestar el ataque de Rajoy de que no hace nada. Los papeles están muy bien delimitados: Rajoy como atacante, Zapatero como

9. Sobre la función indirecta de la pregunta véase Brown-Levinson (1987), Fuentes Rodríguez (2010 $a$, e. p.), Burguera (2009), Rasiah (2010), entre otros. 
el argumentador, la persona comedida, mesurada, que no se sale del buen tono (vid. Fuentes Rodríguez, 2009 a, 2010 c):

El señor RAJOY BREY: Señor presidente, usted no ha dicho la verdad. (Rumores.) Tengo aquí el informe de la Intervención General del Estado de ayer que dice lo siguiente: los ingresos impositivos totales experimentan un aumento del 0,8 , tasa que se sitúa en un descenso del 0,5 en términos homogéneos, una vez ajustadas las devoluciones a sus respectivas campañas. (Aplausos.) Señor presidente del Gobierno, usted no dice la verdad cuando habla del déficit público, porque la Intervención General del Estado dice que el déficit de caja ha aumentado un 37 por ciento, y el déficit de contabilidad nacional un 15 por ciento. Por tanto, yo le digo que usted ha dicho mentira en esta Cámara. (Rumores.- Protestas.)

Dicho esto, señor presidente del Gobierno, como usted muy bien ha dicho en esta Cámara, el termómetro para medir la eficacia de unas medidas económicas es la creación de empleo, con lo cual sus medidas económicas son lisa y llanamente una catástrofe. Ayer dijo usted en el Senado que el paro había tocado techo. Yo le digo una cosa: usted ha tocado suelo en su credibilidad y en su capacidad para afrontar la crisis económica, y le está haciendo un daño descomunal... (Rumores.-Prolongados aplausos.) [...]

El señor PRESIDENTE DEL GOBIERNO (Rodríguez Zapatero): Muchas gracias, señora presidenta. Señor Rajoy, me reafirmo en los datos que afectan a los ingresos del primer trimestre y a la relación con el déficit, si usted los lee bien y no toca de oído, como ha hecho en esta intervención (Aplausos.-Varios señores Diputados: ¡Bien!-Rumores.)

La señora VICEPRESIDENTA: Por favor.

El señor PRESIDENTE DEL GOBIERNO (Rodríguez Zapatero): Dos, me reafirmo en que las expectativas del Gobierno son que la tasa de paro ha llegado a su nivel más alto en este primer trimestre, y que vamos a tener una reducción de la tasa de paro, que es el gran objetivo. (Rumores.)

La señora VICEPRESIDENTA: Señorías, por favor.

El señor PRESIDENTE DEL GOBIERNO (Rodríguez Zapatero): Y por último le pediría que, ante el gran esfuerzo de crear empleo, usted y su partido tengan una política un poco más constructiva... (Aplausos.) (DSCD 159, 28-4-2010, 8)

Rajoy es mucho más descortés que él, pero su función en la cámara lo legitima para ello. Es descortesía funcional, de rol.

\section{Preguntas dirigidas a ministros}

Es el caso de preguntas dirigidas a los ministros la relación es más directa y desciende a la descortesía. La jerarquía de poder parece actuar aquí también de forma muy clara. Entre ellos encontramos una mayor variedad, dependiendo de: 
- La personalidad de cada diputado. Por ejemplo, el ministro de Justicia es mucho más templado, las señoras Espinosa y Villalobos usan la ironía...

- De la relación entre ellos: hay enfrentamientos muy duros siempre entre Sáenz de Santamaría y De la Vega, Gil Lázaro o Cosidó con Rubalcaba. Hay una tradición intertextual que explica ese tono.

- De la posición del ministro en el gobierno: el rol que desempeña le obliga a una determinada imagen. Así, Rubalcaba como ministro de Interior ahora es mucho más beligerante que cuando era portavoz del grupo parlamentario.

- Por último, la presencia de mayor o menor cortesía depende del estilo personal: véase, por ejemplo, la ministra Chacón o Soraya Sáenz de Santamaría.

Teniendo en cuenta estas variables, encontramos en las preguntas orales las siguientes situaciones:

\section{1.}

Casos de atenuación del enfrentamiento, de mantenimiento de la cortesía. Los mecanismos empleados son: el uso de formas corteses, la ausencia de formas descorteses, como el ataque ad hóminem, o el uso de formas indirectas como la ironía, la broma o el humor: ${ }^{10}$

El señor GONZÁLEZ PONS: Asisten a la sesión los representantes de la hostelería y de los trabajadores de hostelería de Valencia. Señora ministra, si usted piensa que los restaurantes, terrazas y chiringuitos de las playas españolas no caben en la Ley de Costas, cambie la Ley de Costas, pero no destruya 45.000 puestos de trabajo a lo largo de toda España, 5.000 solo en la provincia de Valencia. (Rumores.)

La señora VICEPRESIDENTA: ¡Por favor!

El señor GONZÁLEZ PONS: Porque España en este momento no está para que un miembro de su Gobierno, con una decisión política, contribuya aún más a la destrucción de empleo. (Aplausos.) [...]

La señora MINISTRA DE MEDIO AMBIENTE, Y MEDIO RURAL Y MARINO (Espinosa Mangana): Gracias, señora presidenta.

Señoría, usted, que además es abogado, debería conocer la ley, y la ley hace compatibles instalaciones hoteleras con la Ley de Costas. Por tanto, no son necesarios cambios legales, simplemente que todos cumplamos la ley. (DSCD 159, 11)

10. En este último caso tendremos que calibrar si estamos ante un caso de atenuación o de intensificación. 
El primer intercambio presenta una petición con una acusación encubierta: «va a destruir empleo». No es una pregunta como tal. Se usan formas indirectas y se mantiene la cortesía en las formas. La ministra responde con otro argumento acusando bajo la forma de una recomendación: «debería conocer la ley...».

A partir de aquí, el enfrentamiento es más fuerte, aunque indirecto. González Pons presenta razones para no aplicar la ley de costas y termina con una invitación a comer. Plenamente cortés, aunque el contexto lo haga inadecuado y desplace su contenido a un segundo significado:

El señor GONZÁLEZ PONS: Señora ministra, le voy a dar cinco razones por las cuales usted debería no arruinar la vida de los empresarios hosteleros de la costa española (Varios señores diputados: ¡Ah!), y en particular de la costa valenciana. (Protestas.) Primero, por razones ecológicas, porque los restaurantes de playa contribuyen a la sostenibilidad de nuestras costas. En segundo lugar, por razones turísticas, [...]. En tercer lugar, por razones administrativas, [...]. En cuarto lugar, por razones simbólicas, [...] Y en quinto lugar, por los trabajadores,[...] Como no se puede legislar sobre lo que no se conoce, y los políticos debemos estar en la arena política, en la calle, y no en la moqueta, yo voy a cambiar el sentido de mi pregunta y le voy a decir: señora ministra, conozca aquello que va a arruinar. (La señora Monteserín Rodríguez: ¡Qué demagogo!) Yo les invito al señor Rodríguez Zapatero -que va poco por Valencia, pero allí arma mucho lío- y a usted a comer a la playa de Valencia, a un restaurante. Cuando ustedes hayan visto aquello que van a arruinar quizá cambien de opinión. (La señora Monteserín Rodríguez: Al Cabanyal.) ¿Acepta? (Aplausos.) (ídem)

La ministra responde de forma correcta y apela al humor también, aunque con ataques encubiertos:

Señoría, le diré que conozco perfectamente la realidad, pero también conozco la ley, y a lo mejor usted conoce una parte de la realidad y no quiere ni leer la ley. [...] Quiero decirle una cosa y es que desde el ministerio queremos hacer compatible la sostenibilidad de nuestra costa con espacios para los ciudadanos, pero también con la preservación de las actividades económicas legales y regulares. Lo estamos haciendo en toda España. Me extraña, señoría, que en el único sitio donde estemos teniendo problemas sea en Valencia. Usted me va a entender por su origen y espero que comparta conmigo que no es posible con la actual normativa -me estoy refiriendo a la Ley de Costas- hacer un traje a medida en cada lugar y en cada circunstancia (Risas.), a no ser que usted quiera convertir y utilizar las administraciones y las leyes como correa de transmisión (Risas y aplausos.) de intereses particulares e individuales y no desde luego en la defensa de los intereses generales, el uso... (Prolongados aplausos.) (ídem) 
El caso más claro de ataque, aunque atenuado por a lo mejor es: «a lo mejor usted conoce una parte de la realidad y no quiere ni leer la ley». Pasa a la emoción con: «Me extraña que en el único sitio donde estamos teniendo problemas sea en Valencia», y a partir de ahí establece un comentario metafórico que provoca la risa y los aplausos, en una clara referencia a la trama Gürtel. No acusa, es indirecto, pero hace inferir la acusación. Es un caso claro en que las formas indirectas (el promover inferencias, el humor) puede ser más rentable que el ataque claro. No es descortesía, pero sí ataque, enfrentamiento argumentativo, no ad hóminem, pero sí a la imagen del grupo político al que pertenece.

\subsection{Casos de enfrentamiento personal}

En otras ocasiones el enfrentamiento es brutal. Las acusaciones son directas, con ataques directos a las personas. Es lo que ocurre con Soraya Sáenz de Santamaría y Fernández de la Vega.

\subsubsection{Ataque ad hóminem en ambos casos}

La señora SÁENZ DE SANTAMARÍA ANTÓN: Muchas gracias, presidente.

Voy a aprovechar, dado que estamos en racha con el presidente del Gobierno, para ver si hoy obtengo una respuesta sobre una cosa que le llevo pidiendo desde hace tiempo a la señora De la Vega. Un ejemplo muy claro de cómo entiende la señora De la Vega sus relaciones con esta Cámara, sus relaciones con el Poder Legislativo, es un caso conocido como el caso Faisán.

El pasado 28 de octubre usted, la vicepresidenta primera del Gobierno, no respondió a una pregunta que yo le hice en esta Cámara, en esta misma casa, alegando incompetencia. El ministro Rubalcaba, desde entonces, ha venido combinando el escapismo parlamentario con la falsedad. Y el pasado miércoles, precisamente a preguntas de mi grupo parlamentario, el ministro de Justicia despachaba el tema diciendo que son solo rumores. No sé si necesitará que le recuerde lo que dijo la Audiencia Nacional el pasado lunes. La Audiencia Nacional dijo que lo que ustedes llaman rumores es un caso de gravedad, y cito textualmente, sin precedentes en la historia de la lucha contra el terrorismo en España. Por eso, señoría, creo que hoy usted debe dar una respuesta en esta Cámara. Y debe darla porque la policía no puede seguir siendo comprometida por ustedes con su silencio. Y debe darla porque no se puede poner en entredicho el prestigio del Estado de derecho, que es el principal instrumento de algo que creo que compartimos todos, que debe ser una lucha unánime y sin cuartel contra el terrorismo. Yo le pregunto porque estoy en el ejercicio de mi obligación democrática como representante del Poder Legislativo de someter a control las acciones del Ejecutivo y especialmente 
velar por que el Ejecutivo cumpla siempre, siempre la legalidad en el ejercicio de sus funciones. Yo estoy cumpliendo con mi obligación haciéndole esta pregunta. Espero que usted hoy cumpla con la suya. Muchas gracias. (DSCD 140, 48)

La intervención de la Sra. Sáenz de Santamaría es una clara muestra de descortesía y ataque parlamentario a la imagen de su interlocutora y del grupo político al que pertenece. Para ello utiliza los siguientes mecanismos:

- Destruye la imagen del presidente del gobierno con expresiones tremendamente coloquiales, y que banalizan la realidad: «Aprovechar», «estamos en racha» provocan la impresión de que están teniendo suerte, no de que Zapatero ha respondido amablemente. Quita valor a lo que ha hecho Zapatero y lo deja como algo anecdótico, rebaja su imagen.

- Destruye la imagen de De la Vega acusándola de no responder: «la respuesta que le llevo pidiendo desde hace tiempo». Este complemento, «desde hace tiempo», actúa como un elemento desrealizante. Justifica su insistencia, incluso legitima su agresividad, ya que la otra persona se presenta como no colaborativa, incluso como no cumpliendo su función política: alejarse de los ciudadanos, no ser clara, lo cual deja inferir comportamientos negativos. Así quita fuerza a lo que va a decir la señora De la Vega, predispone al receptor en contra, previene que no va a tener respuesta, deja inferir que esta persona no responde. Es decir, destruye primero la imagen de grupo, atacando a Zapatero y relacionándolo con la vicepresidenta, y luego destruye la de esta, antes incluso de que interviniera.

- La nombra en tercera persona, la hace objeto de discurso y se dirige a los diputados de la Cámara, en una clara violación discursiva, ya que se trata de una pregunta oral, un encuentro dialógico.

- Destruye la imagen de otros miembros de su grupo: acusa a De la Vega de «alegar incompetencia», a Rubalcaba de «escapismo y falsedad». El ministro de Justicia «despachaba» el tema, usando un término coloquial, valorativo, despectivo.

- Emplea un léxico muy coloquial y valorativo: «aprovechar, estar en racha, despachar». ${ }^{11}$

- Demuestra su argumentación de que eran rumores, utilizando argumentos de autoridad: la Audiencia nacional, y con citas directas.

11. Así, Hernando Cuadrado (2004) indica que el estilo usado por los políticos es llano cuando refiere hechos favorables para él, su partido, o la correspondiente institución del poder, o censura actitudes de sus adversarios, pero cuando está «en una situación comprometida o adversa, recurre a la ambigüedad en la expresión» (121). Y en la comunicación interna, en cuestiones concretas, usa un lenguaje técnico. 
A partir de ahí pide que le dé una respuesta: «por eso, señoría, creo que hoy debe dar una respuesta...», pero no ha hecho pregunta. Añade razones: «Y debe darla porque... Y debe darla porque...», repetido para dar más fuerza. Luego justifica su pregunta. Curiosamente, gran parte de la pregunta no es tal, sino una narración dirigida a la cámara porque se refiere a De la Vega en tercera persona, solo pasa a ella cuando llega a: «por eso, señoría, creo que usted...».

La estructura comunicativa de este texto es compleja. Y supone también una manipulación. Hay dos receptores: la Cámara sola, y la Cámara incluyendo a De la Vega. Y en teoría es una pregunta directa. ¿Por qué hace esto? Es una estrategia de acusación, que es el fin de la pregunta, porque no espera en realidad respuesta, sino evidenciar que no la hay, para acusarla ante el resto de diputados. El tono condescendiente, de poder, muestra un lenguaje coloquial, minusvalorador, y los imperativos dan una imagen de mujer impositiva, que domina y obliga a los demás. Al final termina con: «Espero que usted hoy cumpla con la suya», obligándole a actuar, dejándole sin salida.

La Sra. de la Vega responde de forma indirecta y genérica: «El gobierno...». Devuelve la acusación: "Ya sé que ustedes...» y deja sin respuesta directa, en clara actitud evasiva (Rasiah, 2010; Fuentes Rodríguez, 2010 a):

La señora VICEPRESIDENTA PRIMERA DEL GOBIERNO, MINISTRA DE LA PRESIDENCIA Y PORTAVOZ DEL GOBIERNO (Fernández de la Vega Sanz): Señoría, el Gobierno ejerce siempre sus responsabilidades y somete su gestión al control del Parlamento. El debate de esta mañana es un buen ejemplo. Ya sé que ustedes no quieren darse por enterados porque solo les gusta echar leña al fuego. Le diré: en catorce ocasiones el Gobierno ha contestado a su pregunta. Hoy volverá a contestar. Por tanto, ahí tiene la respuesta. (Aplausos.) (ídem, 49)

La Sra. Sáenz de Santamaría vuelve a buscar la respuesta directa, a acusar directamente, y a actuar con amenazas: «Escúcheme cuando le digo...».

\section{La señora SÁENZ DE SANTAMARÍA ANTÓN:}

Señora De la Vega, vuelve a eludir usted una respuesta directa en un caso tan claro y en que tiene usted la respuesta tan fácil. El silencio no va a librar de sospechas la actuación de algunos. Y escúcheme bien cuando le digo que solo quien tiene algo que esconder en el Gobierno trata de ocultar la verdad en el Parlamento. (Aplausos.) Solo en ese caso. Hay muchísimas preguntas sin respuesta, pero hoy lo tiene bien fácil si quiere estar a la altura de las circunstancias. La respuesta es muy sencilla. Yo le pregunto: ¿Ha habido alguna instrucción política detrás del chivatazo a ETA? Basta con que me diga usted, aquí y hoy, si sí o no. (Aplausos.) (ídem)

Esta intervención crea un ambiente tenso, por lo que la respuesta también es claramente de ataque. Llegamos a lo descortés, porque aparecen formas que 
abren y cierran su intervención, con función impositiva o directiva («escúcheme bien lo que le digo»). Son actos de habla de reconvención, expresados en estructuras nominales que le dan más fuerza e inmediatez a lo dicho y claramente directas: «Señoría, lecciones de democracia, las justas». Termina con: «Así que menos aspavientos demagógicos y menos remilgos carnavaleros y más trabajar, señoría, que es lo que tienen que hacer ustedes». Aparte, hay interrupciones de otros diputados, protestas, incluso una pregunta directa de otro miembro del parlamento a la que ella responde: («Un señor diputado: ¿Sí o no?») Ya he dicho no. Por tanto, ya he contestado a su pregunta concreta.» Dado que en el Parlamento el orden de palabras está claramente establecido, aquí se produce una usurpación del turno, una alteración de su función interactiva. Las protestas igualmente provocan un debate apasionado, en el que el otro grupo jalea a su portavoz, y actúa como un argumento emocional. Se le presiona, y por ello la respuesta es de enfado, más cercana a la conversación coloquial que a la lógica parlamentaria.

Tras esto, las acusaciones se mueven en la contraposición habitual del debate político: ustedes/nosotros. De la Vega intenta destruir las argumentaciones de su contrincante. Ante el argumento de antidemocracia, lo demuestra con su carácter participativo, con haber hecho una realidad más plural, con no imponer. De la Vega termina con un consejo que responde al «escúchame» de Sáenz de Santamaría: «le recordaré». Es más cortés, es una estrategia indirecta, para llegar a la conclusión que sigue, que ya sí es directa y coloquial: «Así que menos aspavientos demagógicos...», con estructuras nominales que provocan mayor inmediatez:

La señora VICEPRESIDENTA PRIMERA DEL GOBIERNO, MINISTRA DE LA PRESIDENCIA Y PORTAVOZ DEL GOBIERNO (Fernández de la Vega Sanz): Señoría, lecciones de democracia, las justas (Protestas.) No, no.

El señor PRESIDENTE: Silencio, por favor.

La señora VICEPRESIDENTA PRIMERA DEL GOBIERNO, MINISTRA DE LA PRESIDENCIA Y PORTAVOZ DEL GOBIERNO (Fernández de la Vega Sanz): Este Gobierno ha hecho del Parlamento. (Un señor diputado: ¿Si o no?) Ya he dicho no. Por tanto, ya he contestado a su pregunta concreta. Este Gobierno ha hecho del Parlamento el centro del debate político y las relaciones que tenemos entre los dos poderes son unas relaciones que se guían por tres principios: independencia, colaboración y control. Tres premisas que el Gobierno no solo cumple, que no todos pueden decir lo mismo, porque por sus obras les conoceréis. (Una señora diputada: ¡Ojalá!) Y si quiere le doy algún ejemplo de ustedes. Fíjense, en apenas una legislatura y media el presidente del Gobierno ha comparecido aquí en esta Cámara en 57 ocasiones. Ustedes necesitaron ocho años para hacerlo cincuenta. Eso sí que es cultivar una relación. Por no hablarle, si quiere, del control del Senado, en donde a su presidente no se le vio ni en una sola vez en ocho años. En 2.920 días no dijeron ni pío, señoría. (Rumores.) 
El señor PRESIDENTE: Silencio, por favor.

La señora VICEPRESIDENTA PRIMERA DEL GOBIERNO, MINISTRA DE LA PRESIDENCIA Y PORTAVOZ DEL GOBIERNO (Fernández de la Vega Sanz): Hoy hay más control, más transparencia y más debate que cuando ustedes gobernaban. (Rumores.) Si, lo hay. Hoy hay más control, hoy hay más pluralidad, porque aunque es verdad que ustedes están más con los valores absolutos, la ciudadanía está más con la pluralidad. Por supuesto que el Gobierno respeta al Parlamento, pero respetar no es imponer, que es lo que ustedes hacían cuando gobernaban y lo que pretenden hacer también cuando no gobiernan. Le recordaré que, por ejemplo, para determinar qué número de ministerios hay que crear hay que ganar antes las elecciones. Así que menos aspavientos demagógicos y menos remilgos carnavaleros y más trabajar, señoría, que es lo que tienen que hacer ustedes. (Aplausos.) (ídem)

Este tono es habitual en los enfrentamientos entre estas dos diputadas. Así, en esta otra pregunta, cuyo texto rezaba: «¿Qué grado de responsabilidad tiene la vicepresidenta en la absoluta falta de rigor del gobierno de José Luis Rodríguez Zapatero?», pasa a una crítica completa: «Y yo le pregunto ¿cree usted, señoría, que un asunto tan serio como las pensiones de los españoles puede abordarse con tan poco rigor?». Esto va precedido, como es costumbre en ella, de una narración de hechos negativos:

El viernes 29 de enero usted, señora De la Vega, en rueda de prensa después del Consejo de Ministros, anunció a todos los españoles que la nueva edad de jubilación iba a ser los 67 años.[...] Por si había alguna duda del anuncio, el comité federal del Partido Socialista se reunió al día siguiente y ratificó la medida, es decir, que la iniciativa, que era antisocial el viernes, era plenamente socialista el sábado, plenamente socialista, señoría. El domingo no lo tenían ustedes tan claro. El lunes pasó a ser una mera propuesta, y a día de hoy, pese a lo que diga Zapatero, los españoles no tenemos claro si tienen ustedes alguna idea de lo que van a hacer con las pensiones. Yo le pregunto ¿por qué lo hicieron? Si era tan necesario alargar la edad de la jubilación, como decía Zapatero, ¿por qué rectificaron después? Y si no era necesario, ¿por qué generaron tantísima alarma? (DSCD 137, 10-2-2010,9)

En la segunda intervención Sáenz de Santamaría le dice: «Señoría, la crisis tiene solución, pero lo suyo, lo de su Gobierno no tiene remedio». Ello hace que De la Vega también responda con otro argumento emotivo, con otra evaluación:

La verdad es que resulta penoso comprobar que pase lo que pase siguen ustedes en lo mismo, en lo suyo, pensando exclusivamente en la tajada electoral: penoso, señoría; verdaderamente penoso. (Rumores.) Hay que ver qué poco les importa a ustedes su país. En lugar de hablar de reducción de altos cargos, que siempre lo están diciendo, díganselo a los que gobiernan en las comunidades autónomas, díganles que rebajen los cargos y rebajen los gastos y que creen más empleo. 
(Aplausos.) [...] Deben dejarse de tantos jueguecitos artificiales y ditirambos, porque cuando ustedes gobernaban, ¿sabe cuál era el debate? Si se privatizaban o no se privatizaban las pensiones. (Protestas.) [...] ¿Saben qué es lo que les pasa? Que les puede el ansia, la gula de poder. (Fuertes rumores.- Aplausos). ${ }^{12}$ (ídem, 10)

Las evaluaciones actúan como un argumento falaz (vid Plantin, 1998; Lo Cascio, 1998; Lausberg, 1993; Perelman-Olbretchs Tyteca, 1994), pero son muy frecuentes en el discurso político.

En otros casos la acusación ad hóminem es clara. Así, en la siguiente pregunta, el Sr. Cosidó hace preceder su pregunta de su acusación al Secretario de Estado de Seguridad, con términos claramente inadecuados y un grado elevado de ironía, que raya en el sarcasmo.

El secretario de Estado de Seguridad se ha declarado amnésico y además no parece que tenga mucha voluntad de venir a esta Cámara a explicar de qué hablaron. Mi pregunta, señor ministro, es si en esas conversaciones se habló del denominado caso Faisán. (DSCD 140, 53)

Luego ataca directamente al ministro acusándole de Houdini parlamentario:

Por tanto, señor ministro, usted es un Houdini parlamentario pero yo creo que hay muchos españoles hoy esperando que usted dé una respuesta convincente, y si usted no puede o no quiere dar esa respuesta convincente a esta situación absolutamente anómala creo que lo menos que tiene que hacer es cesar al secretario de Estado porque lo que España no puede permitirse es tener a un secretario de Estado de Seguridad bajo sospecha. (ídem)

El ataque a la imagen de ambos es claro. A ello siguen otra crítica velada y una acusación indirecta:

Para derrotar al terrorismo, señor ministro, no valen ni el atajo de la guerra sucia ni el atajo de la paz sucia, lo que vale es la firmeza del Estado de derecho, nuestras convicciones democráticas y la defensa de las víctimas -por cierto, le eché de menos en el congreso de Salamanca. (ídem)

Deja entrever que no está con las víctimas. Y continúa con la imposición y la exigencia: «Con la misma firmeza que le estamos apoyando en su política antiterrorista, le exigimos que asuma sus responsabilidades en este caso que jamás debió ocurrir».

12. Texto completo en http://www.congreso.es/portal/page/portal/Congreso/Congreso/Publicaciones/DiaSes/ Pleno. 
La imagen que da Cosidó es de fuerza y poder frente al ministro. Sin embargo, su posición en la Cámara no es tal. No corresponde a una realidad, sino a su papel parlamentario de oposición. La respuesta muestra una posición de poder y fuerza pero argumentando:

Señor Cosidó, creo que he contestado catorce veces a preguntas parlamentarias de usted y de su compañero Gil Lázaro sobre este tema. Es más, creo que en los últimos meses, desde septiembre, solo he contestado preguntas parlamentarias de este tema, de usted y del señor Gil Lázaro. Por tanto, Houdini parlamentario, cero; es más, el martes estuve en el Senado, cero. (ídem)

Y termina acusando también, pero de forma indirecta. Es, por tanto, menos descortés, aunque con la misma eficacia, ya que su poder está legitimado:

Finalmente le diré algo más: que el director general de la Policía y el secretario de Estado de Seguridad hablen es lo normal, todos los días, por la mañana, por la tarde y por la noche. ¿Qué tiene eso de raro? No tiene nada de raro, salvo que alguien tenga en la cabeza insidias políticas, que es lo que usted hace una y otra vez en esta Cámara desde hace algunos meses, contra los policías, contra los jueces, contra los fiscales y ahora contra los responsables del Ministerio del Interior; insidias políticas, señor Cosidó, esa es su especialidad en esta Cámara. (ídem, 53-54)

\subsubsection{Ataque vs. indirección. Forma cortés y contenido descortés}

El señor BURGOS GALLEGO: Gracias.

Señor ministro, ¿considera el Gobierno que las continuas filtraciones sobre el sistema de pensiones generan confianza en trabajadores y pensionistas?

El señor MINISTRO DE TRABAJO E INMIGRACIÓN (Corbacho Chaves): Señoría, el Gobierno no ha hecho ninguna filtración; ha tomado un acuerdo en el Consejo de Ministros. Gracias. (DSCD 137, 19)

La primera parte de esta pregunta oral se mantiene con las formas corteses, aunque el Sr. Burgos deja inferir acusaciones graves a la presuposición de las filtraciones. La respuesta intenta anular dicha presuposición. Es una maniobra hábil de ataque: plantear como realidades predeterminadas lo discutible (Fuentes-Alcaide, 2002; Van Dijk, 2003). A continuación acusa directamente al gobierno:

Con sus vaivenes, con sus imprudencias y con su desorden han contaminado completamente la atmósfera del Pacto de Toledo. Los ciudadanos están que trinan, con toda la razón, con unas propuestas que usted dice públicamente que no son las suyas, que otros filtran, que otros presentan, que otros modifican y que otros niegan. (ídem) 
Al final de su intervención pasa al ataque ad hóminen. Las formas son todas corteses: «yo le deseo toda la suerte del mundo... descanse en paz.»Y usa sus mismas afirmaciones. Pero la inferencia es: «usted está muerto políticamente»:

Señor ministro, yo le deseo toda la suerte del mundo en lo personal, en lo político usted ya tiene su epílogo escrito con sus propias frases: «De ninguna de las maneras llegaremos a 4 millones de parados», enero de 2009. «Radicalmente no alargaremos la edad de jubilación», 9 de enero de 2010. Descanse en paz... (Aplausos.) (ídem, 20)

La respuesta está basada entre el ataque y las formas corteses: le invito... no quiero/tenga un mínimo de rigor/no diga falsedades/deje de decir falsedades, el único... es usted:

El señor MINISTRO DE TRABAJO E INMIGRACIÓN (Corbacho Chaves): Señor diputado, cuando cite alguna declaración mía tenga un mínimo de rigor y no diga falsedades. Esa declaración hacía referencia al año 2009, referido al paro registrado. Le invito a que consulte a 31 de diciembre el paro registrado y lo ponga en relación con lo que dije en ese momento. No quiero hacer de ello un debate, pero deje de decir falsedades y menos en esta Cámara. Señor diputado, el único que ha sembrado dudas desde el primer momento en esta Cámara sobre el futuro de las pensiones ha sido usted. (ídem)

O el mandato final: «Señor diputado, un poco más de rigor». En esta otra pregunta se comienza respetando lo establecido:

Señora ministra de Defensa, ¿considera que se están cumpliendo las previsiones de despliegue de la protección de las tropas en escenarios de guerra? (Sr. Fernández de Mesa, DSCD 140, 52)

A lo que responde la ministra de forma directa, también: «Escrupulosamente, señoría». Esta respuesta tajante muestra una actitud de fuerza, lo que puede interpretarse como manifestación de poder, legitimado por su posición, pero poco cortés, ya que faltan formas de enlace con el otro intercambio. Esto crea ya un clima de enfrentamiento que se manifiesta de forma clara en el segundo intercambio. Así, el Sr. Fernández de Mesa comienza ofreciendo datos sobre la muerte de 30 soldados, que terminan en una petición:

Hablando de seguridad y de protección, señora ministra, le hago una petición: que ni un soldado español más se vuelva a subir a un BMR para realizar las misiones que hasta este momento los han puesto en peligro e incluso han pagado con su vida. Esta es la petición: retírense los BMR de las misiones que están realizando y donde están muriendo soldados españoles hasta que usted ponga los RG-31 a plena 
disposición de las Fuerzas Armadas o mientras no se utilicen otros carros de otros ejércitos como, por ejemplo, los Piraña, que no hay intención de utilizarlos.

La petición es clara: ni un soldado más en un BMR mientras haya riesgo de muerte como se está comprobando a lo largo de estos años. (ídem)

La ministra de Defensa le devuelve la acusación inferida de lo anterior, con un ataque (no es culpa de este gobierno sino del anterior) y lo hace con la misma estrategia: preámbulo, o estructura de presentación para hacer más relevante lo que sigue: ¿sabe usted....? Esta no es una pregunta, sino una estrategia de enfatización, y de contraargumentación:

Señoría, ¿sabe usted lo que está pasando? El Gobierno de José Luis Rodríguez Zapatero le está dando una vuelta a una decisión errónea que tomó el Gobierno de José María Aznar, como fue prolongar la vida útil de los BMR, vehículos que ya tenían en aquel entonces treinta años de antigüedad. Fue decisión de su Gobierno. (Aplausos.) ¿Sabe qué ha hecho el Gobierno de Zapatero? Dos cosas. Poner en marcha un plan de renovación de vehículos, el más ambicioso que jamás hayan conocido nuestras Fuerzas Armadas, para tener 575 nuevos blindados más, con una inversión de 321 millones de euros y entre tanto hemos modernizado los BMR para que puedan seguir siendo aptos para la misión. Hemos renovado sus motores, reforzado su blindaje y equipado todos y cada uno de ellos con inhibidores de frecuencia. Gracias a ese esfuerzo hoy existen en Afganistán hasta 94 blindados medio tipo Lince y ya tenemos 34 blindados de pelotón RG-31, que van a llegar hasta 62 unidades en el mes de marzo. Vehículos con la mayor protección antiminas de los que ahora mismo existen en el mercado. De manera que cuando en el mes de marzo llegue a Afganistán el próximo relevo, que es el que se está entrenando ahora para poder utilizar los BMR, no va a haber ni un solo BMR más actuando en Afganistán y estarán los nuevos vehículos en los que ha invertido el Gobierno de José Luis Rodríguez Zapatero. ¿Sabe de cuánto ha sido la inversión? Se lo repito: 321 millones de euros. ¿Sabe cuánto invirtió el Gobierno en ocho años de José María Aznar en nuevos blindados? Cero euros, señoría. (Aplausos.) No solo hemos mejorado los vehículos y hemos puesto en marcha un plan de renovación, es que ahora nuestros soldados acuden a la zona de operaciones en aviones seguros. (Aplausos.) Es que ahora tenemos aviones no tripulados para mejorar nuestra inteligencia, es que además todos ellos llevan inhibidores de frecuencia y nuestras bases cuentan con mejores sistemas de protección. Por tanto, la prioridad del Gobierno de José Luis Rodríguez Zapatero, con hechos, es la seguridad de nuestras tropas. Ahora miremos los dos atrás y al menos coincida conmigo en que ojalá hubiera sido la prioridad del Gobierno de José María Aznar. (Una señora diputada: ¡Muy bien!- Aplausos.) (ídem)

Su respuesta está fuertemente argumentada con datos, y la ministra hace gala de una gran fuerza en ella. Termina con una conminación a que le dé la 
razón: «miremos... y al menos coincida conmigo». Es formalmente cortés, pero hay una acusación clara en la inferencia: «ojalá hubiera sido la prioridad» implica que no lo fue.

La ministra es al inicio cortés, después descortés. Se emplea la cortesía como un mecanismo de conseguir el cambio de tono, la aquiescencia del otro, aunque como una maniobra argumentativa, ya que existe un conocimiento previo entre ellos. Ello ayuda a interpretar la ironía.

\subsection{El grado mayor de descortesía son los insultos directos}

Aunque pueden aparecer en el discurso parlamentario, chocan con la norma general de la sociedad, para la que es un ataque no permitido. Son deliberados «in the sense that they are entended to be perceived and recognised as Duch by the person targeted» (Ilie, 2001: 53). Y muestran las reglas, prejuicios, tabúes, etc., de diferentes grupos sociales o políticos de una comunidad.

Ilie (2004) señala que no son las palabras o frases las que insultan, sino los roles de los interlocutores y la relación con el otro. Así, veíamos en el enfrentamiento Cosidó-Rubalcaba. El primero era más insultante, el segundo se mantenía en una forma apropiada, pero su rol, de poder, hacía que tuviera más fuerza. Y, en el fondo, «It is the uptake of insults, rather than the intrinsic value of insulting utterances themselves that often determines the insulting force of a statement» (Ilie, 2001: 65).

Podemos verlo en la pregunta número 180/000847 del Sr. Conde Roa, en su turno de réplica:

Lo que sucede es que después, en lugar de defender los intereses de la comunidad autónoma, sus compañeros de partido, incitados por un alcalde trabucaire, que ayer convocó una manifestación en la ciudad de Vigo...

El señor PRESIDENTE: Silencio, por favor.

El señor CONDE ROA: ... se dedican, como digo, a utilizar mecanismos del Estado de derecho para condicionar la política de una comunidad autónoma. Es intolerable, señoría, que antes de que se produjese el informe del Consejo de Estado sobre la Ley de Cajas de Ahorro usted dijera que iba a recurrir. (DSCD 137, 13)

El Sr. Conde Roa insulta a un alcalde en su intercambio, a lo que la ministra Salgado responde, rechazando lo no aceptable socialmente:

Señoría, no puedo pasar por alto esta expresión de alcalde trabucaire. (La señora Valenciano Martínez-Orozco: Exacto. Muy bien.- Aplausos.) Quiero decirle que desde luego manifiesto mi más absoluta protesta por la utilización de ese término. 
(La señora Valenciano Martínez-Orozco: Sí señora.) Es un grave insulto que me parece que usted debería de retirar. (Aplausos.) Señoría, el Gobierno está recurriendo una ley, no una fusión. A ver si se enteran. (ídem, 14)

\section{5.}

En las preguntas orales, la situación de partida es una relación jerárquica en la que el Gobierno tiene el poder. En este tipo de texto las reglas del juego implican un ataque de la oposición sobre él, legitimado. Por tanto, la descortesía en el que pregunta se espera, con lo que su efecto se atenúa. Es normativa. Su imagen no sufre, ya que está permitida por la interacción. Solo si llega ya al insulto. La imagen del gobierno es de colaboración. Es lo que le exige la democracia. Debe responder a lo preguntado y exigido. Si actúa de forma fuerte o impositiva, se evaluaría de forma más descortés. Pero también debe manifestar su poder.

En líneas generales en el lenguaje político, y concretamente en las preguntas orales, encontramos:

- Rituales de cortesía en el aspecto interactivo: tratamiento de usted..., respeto al orden de palabra (esto a veces se ve interrumpido, y cada vez encontramos más casos de interrupciones o comentarios del grupo contrario. Son breves y llenos de emoción).

- Ataques permitidos, acusaciones de mentir (Van Dijk, 2005, 2007; Blas Arroyo, 2003), de no hacer, de no decir la verdad, de ocultar datos..., pero sin llegar al insulto, de forma correcta, no violenta. La norma sería la descortesía en el fondo, y la cortesía en la forma. Si la descortesía llega a la forma, se potencia. Por ejemplo, el tono de voz, que sería el rasgo más descortés, en el discurso político es moderado, por eso sirve para rebajar la tensión. Si se intensifica, como no es lo esperado, se entiende que el enfado es mayor. Aquí no tiene el atenuante de la emoción, como en una conversación coloquial, porque estamos en un tipo de discurso formal, perfectamente planificado. Ahora bien, en el turno de dúplica, donde ya no hay planificación, la emoción sale a veces y provoca un discurso violento e inadecuado desde el punto de vista normativo. Esto es frecuente en las preguntas orales, donde no hay preparación previa y sí una inmediatez en el tiempo, que puede hacer reaccionar de forma muy descortés.

- Situación esperada de enfrentamiento, que rebaja la fuerza de los ataques.

- Lenguaje culto, que sirve para atenuar la descortesía: queda dentro de lo aceptado, de lo permitido entre seres civilizados. 
Las formas más frecuentes en las preguntas orales son las indirectas. Estas, según Brenneis (1986) pueden ser de tres tipos: centrada en el texto, en la voz, en la audiencia o en los sucesos. Así, puede hacerse a través de mecanismos lingüísticos: la vaguedad (Channell, 1994; Fuentes Rodríguez, 2008; Gruber, 1993; Van Dijk, 2003), la ocultación del enunciador (el grupo) remitiéndose al receptor (como hace Sáenz de Santamaría dirigiéndose a la Cámara), o la atenuación, y sobre todo la impersonalización o generalización, apuntando a la imagen de grupo, con lo que el ataque también se reduce. Este caso es muy frecuente en las respuestas del Ejecutivo. De esta forma se atenúan los posibles efectos negativos que pudiera tener. Es un mecanismo de evasión y una forma de salvar su imagen, que es la que está en peligro en este tipo de discursos. Lo preferido para vencer en esta lucha es mantener las formas y ser colaborativo.

\section{Referencias bibliográficas}

Arce Castillo, Á. (2006): El lenguaje político. Recursos pragmáticodiscursivos en registros formales e informales, Salamanca, Ratio Legis.

Bayley, P. (ed.) (2004): Cross-Cultural Perspectives on Parliamentary Discourse, Philadelphia, J. Benjamins P.C.

Blas Arroyo, J. L. (2003): «Perdóneme que se lo diga, pero vuelve usted a faltar a la verdad, señor González»: form and function of politic verbal behaviour in face-to-face Spanish political debates», Discourse \& Society, 14(4): 395-424.

Boulton, C. (1992): «Rules and conventions», The House Magazine, 2: 8.

BRAVo, D. (2001): «Sobre la cortesía lingüística, estratégica y conversacional en español», Oralia, 4: 299-314.

Bravo, D. (ed.) (2005): Estudios de la (des)cortesía en español. Categorías conceptuales y aplicaciones a corpora orales y escritos, Buenos Aires, Editorial Dunken.

Bravo, D; A. BRIz (eds.) (2004): Pragmática sociocultural: estudios sobre el discurso de cortesía en español, Barcelona, Ariel.

BRENNEIS, D. (1986): «Shared territory: audience, indirection and meaning», Text 6(3): 339-347.

Brown, P; S. C. Levinson ([1978]1987): Politeness. Some Universals in Language Use, Cambridge, Cambridge University Press.

Borthwick, R. L. (1993): «On the floor of the house», in FrankLin, M.; P. NorTON (eds.) (1993: 73-103).

Bull, P. (1994): «On identifying questions, replies and non-replies in political interviews», Journal of Language and Social Psychology 13 (2): 115-131. 
Bull, P. (2003): The Microanalysis of Political Communication: Claptrap and Ambiguity, London, Routledge.

Bull, P.; K. MaYer (1993): «How not to answer questions in political interviews», Political Psychology 14 (4): 651-666.

BURGUERA, J. (2010): Gramática y pragmática de la interrogación retórica en español. Una aplicación al debate parlamentario, tesis doctoral inédita. Barcelona, Univ. Barcelona.

Calvo, C. (1991): Power relations and fool-master discourse in Shakespeare: A discourse stylistics approach to dramatic dialogue (Monographs in systemic linguistics 3), Nottingham, Department of English Studies, University of Nottingham.

Channell, J. (1994): Vague Language, Oxford, Oxford University Press.

Chilton, P. (ed.) (2002): Politics as text and talk. Analytic approaches to political discourse, Philadelphia, J. Benjamins.

Chilton, P. (2004): Analysing Political Discourse, London, Routledge.

Chilton, P.; C. Schäffner (2002): «Introduction: Themes and principles in the analysis of political discourse», en Chilton, P. (ed) (2002: 1-44).

Ducrot, O. (1995): «Les Modificateurs Déréalisants», Journal of Pragmatics, 24: $145-165$.

Emmertsen, S. (2007): «Interviewers' challenging questions in British debate interviews», Journal of Pragmatics 39: 570-591.

Franklin, M.; I. Norton (eds.) (1993): Parliamentary Questions, Oxford, OUP.

Fuentes Rodríguez, C. (2008): «La aproximación enunciativa», LEA, 30 (2): 223-258.

- (2009 a): «El debate entre Zapatero y Rajoy: estudio textual e interactivo», Tonos digital 18,www.tonosdigital.com

- (2009 b): «Parliamentary (im)politeness and argumentative force: «decirles, señorías, que...(to say, sirs, to you, that...)», en Álvarez Benito, G.; G. Fernández Díaz; I. IÑIgo (eds.): Actas del I Congreso Internacional de Estrategias del Discurso Politico/Proceedings of the I International Conference on Political Discourse Strategies, Sevilla, Mergablum. 63-80.

- (2010 a): «Las preguntas orales en el parlamento español», Philologia Hispalensis, en prensa.

- (2010 b): «La aserción parlamentaria: de la modalidad al metadiscurso», Oralia, 13: 97-125.

- (2010 c): «El debate Zapatero/Rajoy: estudio argumentativo», Tonos digital 20.

- (en prensa): «(Des)cortesía e inferencia: los procedimientos indirectos», Ponencia presentada en el Congreso Internacional «Pragmática del español hablado: Nuevas perspectivas de análisis del español coloquial», Valencia, 2009. 
Fuentes Rodríguez, C.; E. AlCAIDe lara (2002): Mecanismos lingüísticos de la persuasión, Madrid, Arco Libros.

- (2008): (Des)cortesía, agresividad y violencia verbal en la sociedad actual, Sevilla, Publicaciones Universidad Internacional de Andalucía.

- (eds.) (2009): Manifestaciones textuales de la (des)cortesía y agresividad verbal en diversos ámbitos comunicativos, Sevilla, Publicaciones Universidad Internacional de Andalucía.

Fuentes Rodríguez, C. et al. (2011): Aproximaciones a la (des)cortesía verbal en español, Berne, Peter Lang.

Goffman, E. (1959): The presentation of self in everyday life, New York, Doubleday.

- (1967): Interaction ritual. Essays on face-to-face behaviour, New York, Doubleday.

Gruber, H. (1993): «Political language and textual vagueness», Pragmatics 3: 1-28.

HARris, S. (1991): «Evasive action: how politicians respond to questions in political interviews», en SCANnElL, P. (ed.): Broadcast Talk, London, Sage, 76-99.

- (2001): «Being politically impolite: extending politeness theory to adversarial political discourse», Discourse and Society 12 (4): 451-472.

Heritage, J. (2002): «The limits of questioning: negative interrogatives and hostile question content», Journal of Pragmatics 34 (10-11): 1427-1446.

- (2003): «Designing questions and setting agendas in the news interview», en P. GLenN ET AL. (eds.): Studies in Language and Social Interaction, Mahwah, NJ., Erlbaum.

Hernando Cuadrado, L. A. (2004): «Tendencias actuales del español en el discurso político», en Sanz SaInz, I.; Á. Felices Lago (eds): Las nuevas tendencias de las lenguas de especialidad en un contexto internacional y multicultural, Current trends of languages for specific purposes in an internacional and multicultural context, Granada, 121-129.

ILIE, C. (2001): «Unparliamentary language: insults as cognitive forms of ideological confrontation», en DiRVEn, R.; R. Frank; C. IliE (eds.): Language and ideology. Volume II: Descriptive cognitive approaches, Amsterdam-Philadelphia, J. Benjamins. 235-263.

ILIE, C. (2004): «Insulting as (un)parliamentary practice in the British and Swedish parlia ments: A rhetorical approach» en BAYLEY, P. (ed.) (2004: 45-86).

Johnson, D. (1992): «Compliments and politeness in peer-review texts», Applied Linguistics 13(1): 51-71.

LAUSBERG, H. (1993): Elementos de retórica literaria, Madrid, Gredos.

Lo Cascio, V. (1991): Gramática de la argumentación, Madrid, Alianza. 
MAY, E. (1989): Treatise on the law, privileges, proceedings and usage of Parliament. (21 edition, edited by C. J. Boulton) London, Butterworth.

Perelman, C.; L. Olbrechts-Tyteca (1994): Tratado de la argumentación, Madrid, Gredos.

Pérez de Ayala, S. (1996): Question Time: Cortesía lingüística en la Cámara de los Comunes, tesis doctoral no publicada, Universidad Complutense de Madrid.

Pérez de Ayala, S. (2001): «FTAs and Erskine May: Conflicting Needs? Politeness in Question Time», Journal of Pragmatics, 33: 143-169.

Plantin, C. (1996): La argumentación, Barcelona, Ariel.

RASIAH, P. (2010): «A framework for the systematic analysis of evasion in parliamentary discourse», Journal of Pragmatics 42: 664-680.

VAN DiJK, T. A. (2000): «Parliamentary Discourse», en WodaK, R.; T. VAN DIJK (eds): Racism at the Top. Parliamentary Discourses on Ethnic Issues in Six European States, Klagenfurt, Austria, Drava Verlag, 45-78.

- (2003): Ideología y discurso, Barcelona, Ariel.

- (2004): «Text and context of parliamentary debates», en BAYLEY, P. (ed.), 339-372.

- (2005): «War rhetoric of a little ally. Political implicatures and Aznar's legitimatization of the war in Iraq», Journal of Language and Politics, 4 (1): 65-91.

- (2007): «La contextualización del discurso parlamentario: Aznar, Iraq y la pragmática del mentir», en CoRTÉs, L. et al.: Discurso y oralidad, I, Anejos Oralia 3/1, Madrid, Arco Libros, 137-163.

WiLson, J. (1990): Politically Speaking: The Pragmatic Analysis of Political Language. Oxford, Basil Blackwell. 